\title{
Diaphragmatic hernias after sequential left ventricular assist device explantation and orthotopic heart transplant: Early results of laparoscopic repair with polytetrafluoroethylene
}

Shawn S. Groth, MD, Bryan A. Whitson, MD, Jonathan D'Cunha, MD, PhD, Rafael S. Andrade, MD, and Michael A. Maddaus, MD

From the University of Minnesota Department of Surgery, Division of Cardiovascular and Thoracic Surgery, Minneapolis, Minn.

Received for publication July 11, 2007; revisions received Aug 23, 2007; accepted for publication Sept 7, 2007.

Address for reprints: Michael A. Maddaus, MD, University of Minnesota Department of Surgery, MMC 207, 420 Delaware St SE, Minneapolis, MN 55455 (E-mail: madda001@umn.edu).

J Thorac Cardiovasc Surg 2008;135:38-43 $0022-5223 / \$ 34.00$

Copyright $\odot 2008$ by The American Association for Thoracic Surgery

doi:10.1016/j.jtcvs.2007.09.017
Objective: Patients who undergo an orthotopic heart transplant after explantation of an intraperitoneal left ventricular assist device are at an increased risk of developing diaphragmatic hernias. The aim of this study was to determine the incidence of these hernias and to evaluate the morbidity and short-term efficacy of laparoscopic repair.

Methods: Using our prospectively maintained database, we performed a singleinstitution, retrospective review of all patients who underwent laparoscopic repair of a diaphragmatic hernia resulting from defects created by left ventricular assist device explantation.

Results: From January 1, 1995 to March 1, 2007, 5 men at our institution (median age, 56 years) out of 97 patients at risk developed a diaphragmatic hernia after left ventricular assist device explantation (5.2\% incidence). The median time to presentation was 25.4 months (range, 9-62 months). The median size of the hernia defect was $8 \mathrm{~cm}$ (range, 6-15 cm). We performed all repairs completely laparoscopically. None of the defects were repaired primarily because doing so would have resulted in significant tension. Instead, we secured a polytetrafluoroethylene patch over the defect with pledget-reinforced, braided, nonabsorbable, handsewn mattress sutures, followed by reinforcement with laparoscopic tacking screws. We noted no perioperative complications. The median length of stay was 2 days (range, 1-4 days). At a median follow-up period of 12.2 months (range, 1-31 months), no recurrences had occurred.

Conclusion: Laparoscopic repair of diaphragmatic hernias with polytetrafluoroethylene can be performed with minimal morbidity and excellent short-term results.

\footnotetext{
A pproximately 5.2 million people in the United States are living with congestive heart failure. ${ }^{1}$ Of those with end-stage congestive heart failure, an orthotopic heart transplant (OHT) is the most efficacious and well-established surgical treatment. However, given the paucity of suitable donor cardiac allografts, only 2191 people (in the United States) underwent an OHT in $2006 .^{2}$ Moreover, decompensated heart failure often requires acute hemodynamic support. Left ventricular assist devices (LVADs), which can provide emergency cardiovascular support that can be continued for extended periods, are now an effective bridge to transplant, allowing for greater than $70 \%$ survival in patients awaiting an OHT. ${ }^{3}$
} 


\section{Abbreviations and Acronyms \\ LVAD = left ventricular assist device \\ OHT = orthotopic heart transplant \\ $\mathrm{OR}=$ operating room}

Depending on their design and the preference of the surgeon, intracorporeal LVADs may be implanted intraperitoneally or extraperitoneally. With an intraperitoneal LVAD, the locations where the inflow and outflow cannulas penetrate the diaphragm (left laterally for inflow and anteriorly for outflow) are prone to herniation after LVAD explantation and subsequent OHT (Figure 1). The reported incidence of diaphragmatic hernias after LVAD explantation is $4.3 \%$ (if the cannula defects are closed at explantation) to $15.9 \%$ (if the cannula defects are not closed at explantation). ${ }^{4}$

Experience with repair of diaphragmatic hernias resulting from LVAD explantation is limited. Thus far, we know of only 2 case reports of an open repair of a diaphragmatic hernia resulting from LVAD explantation, ${ }^{5,6}$ only 1 series of 6 patients who underwent open repair, ${ }^{4}$ and only 1 case report of a laparoscopic repair. ${ }^{7}$ The aim of our current study was to review the incidence of diaphragmatic hernias resulting from intraperitoneal LVAD explantation at our institution and to evaluate the safety, perioperative outcomes, and short-term efficacy of laparoscopic repair.

\section{Materials and Methods \\ Data Collection}

We obtained institutional review board approval. The need for informed consent was waived. With the use of our prospectively maintained database, we performed a retrospective chart review for all patients who developed a diaphragmatic hernia after LVAD explantation since 1995 (the year the first LVAD was implanted in a patient at our institution) and who subsequently underwent repair at our institution. We excluded patients from our analysis who were not at a significant risk for developing a diaphragmatic hernia because they did not undergo LVAD explantation (patients who had an LVAD placed as permanent [destination] therapy and patients who did not survive to undergo an OHT) or because they had undergone implantation of an extracorporeal or intracorporeal extraperitoneal LVAD. We collected data on patient characteristics, perioperative details, and early follow-up findings. The date of diaphragmatic hernia diagnosis was defined as the date on which the results of an imaging study (chest x-ray, computed tomographic scan, or upper gastrointestinal series) confirmed the presence of a hernia. Repair failure was defined by computed tomography evidence of recurrence.

\section{Statistical Analysis}

We report the results as the median with the range in parentheses or the mean \pm standard deviation, where appropriate. With the use of the Statistical Package for the Social Sciences 14.0 for Windows (SPSS Inc, Chicago, Ill), we compared our results with those of a previous study from another institution on the outcomes of open repair of diaphragmatic hernias after LVAD explantation, ${ }^{4}$ using a 2-sample $t$ test for continuous variables $(\alpha=0.05)$ and Fisher exact test for categoric variables $(\alpha=0.05)$.

\section{Results}

\section{Hernia Incidence}

From January 1, 1995 to March 1, 2007, we implanted a total of 288 heart assist devices in 230 patients (Figure 2). Of the 97 patients who later underwent explantation of an intraperitoneal LVAD, 5 developed a diaphragmatic hernia (5.2\% incidence) (Figure 3). During implantation of an intraperitoneal LVAD, our cardiac surgeons create discrete defects in the diaphragm for the inflow and outflow cannulas (Figure 1). Because we close the diaphragmatic cannula defects at the time of LVAD explanation, we compared the hernia incidence in our patients with that reported in the literature when the defects are closed at the time of LVAD explantation $(4.3 \%){ }^{4}$ The hernia incidence in our patients and the reported incidence in the literature were similar $(P=.68)$.

\section{Patient Characteristics}

Five men (median age, 56 years) developed a diaphragmatic hernia after LVAD explantation, even though their diaphragmatic cannula defects had been closed at the time of their LVAD explantation and subsequent OHT (Table 1). Two patients developed a hernia through the inflow cannula defect, and 3 patients developed a hernia through the outflow cannula defect. For all 5 patients, induction immunosuppression included a steroid taper; for maintenance immunosuppression, all 5 patients were receiving mycophenolate mofetil and tacrolimus. ${ }^{8}$ None of the 5 patients were taking long-term steroids. The time to presentation after their OHT varied widely (median, 25.4; range, 9-62.3 months) (Table 1). All 5 patients had developed upper abdominal or lower chest discomfort. Other hernia symptoms included bloating ( 2 patients), borborygmi ( 2 patients), and nausea (1 patient). Because of worsening pain, 1 patient required urgent repair.

\section{Perioperative Details}

The omentum, colon, and stomach were the most common viscera within the hernia sac (Table 1). The median size of the defect was $8 \mathrm{~cm}$ (range, 6-15 cm). None of the defects were repaired primarily because doing so would have resulted in significant tension. Instead, we secured a 2-mm polytetrafluoroethylene patch (Gore Dualmesh, WL Gore \& Associates Inc, Flagstaff, Ariz) over the defect using pledget-reinforced, braided, nonabsorbable, handsewn mattress sutures, followed by reinforcement with laparoscopic tacking screws. The median operating room (OR) time was 219 minutes (range, 182-345 minutes). However, most patients required extensive adhesiolysis. For instance, 1 patient 

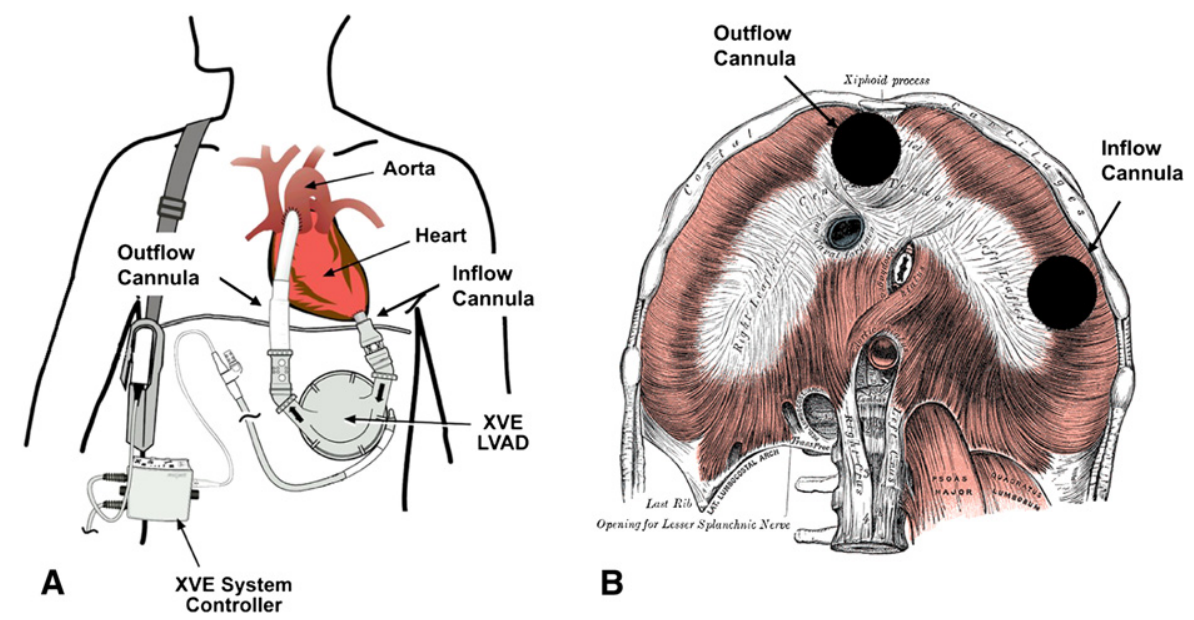

B
Figure 1. Coronal view (A) (adapted with permission from Thoratec Corp, Pleasanton, Calif) and axial view (B) (adapted from Gray's Anatomy of the Human Body, 20th Ed, accessed from http://en. wikipedia.org/wiki/lmage:Gray391.png) demonstrating the relationship of the LVAD inflow and outflow cannulas to the diaphragm. $L V A D$, left ventricular assist device. required 3 hours of adhesiolysis to free his colon from the surface of his cardiac allograft. Blood loss was minimal (median, $50 \mathrm{~mL}$; range $20-50 \mathrm{~mL}$ ). We noted no perioperative complications. Postoperatively, all 5 patients were able to resume oral intake immediately and had a short length of stay (mean, $2.6 \pm 1.3$ days) (Table 1). Compared with a published series of open repair of diaphragmatic hernias resulting from LVAD explanation (mean length of stay, $7.8 \pm 2.2$ days $),{ }^{4}$ the length of stay in our series of laparoscopic repair was significantly shorter $(P=.001)$.

\section{Early Follow-up}

At a median follow-up time of 12.2 months (range, 1-31 months) (Table 1), none of our patients had radiographic evidence of hernia recurrence (Figure 4). All 5 patients were seen for routine follow-up at our institution's cardiac

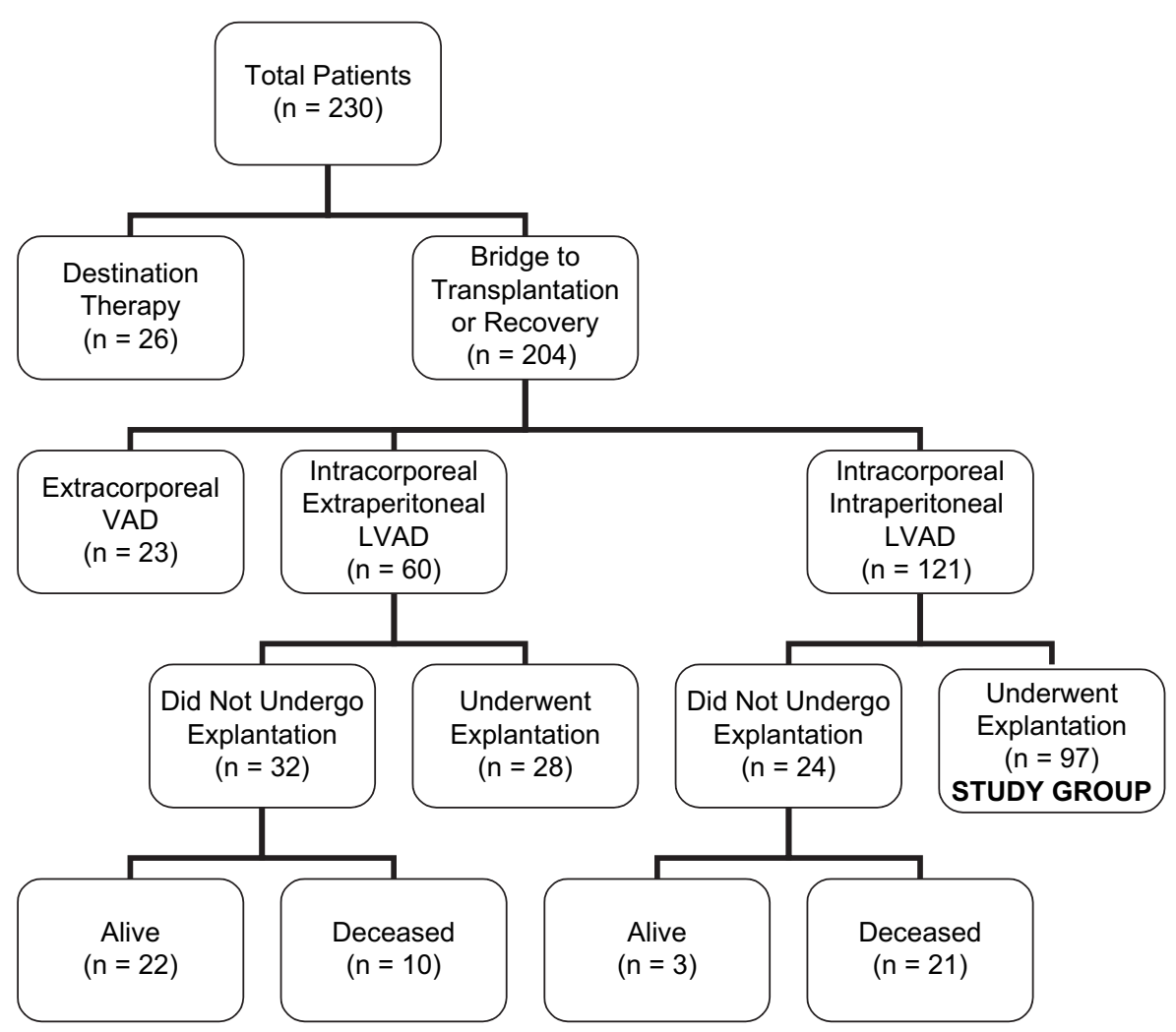

Figure 2. Distribution of extracorporeal VADs and intracorporeal LVADs performed at the University of Minnesota from January 1, 1995, to March 1, 2007. VAD, Ventricular assist device; LVAD, left ventricular assist device.

40 The Journal of Thoracic and Cardiovascular Surgery • January 2008 

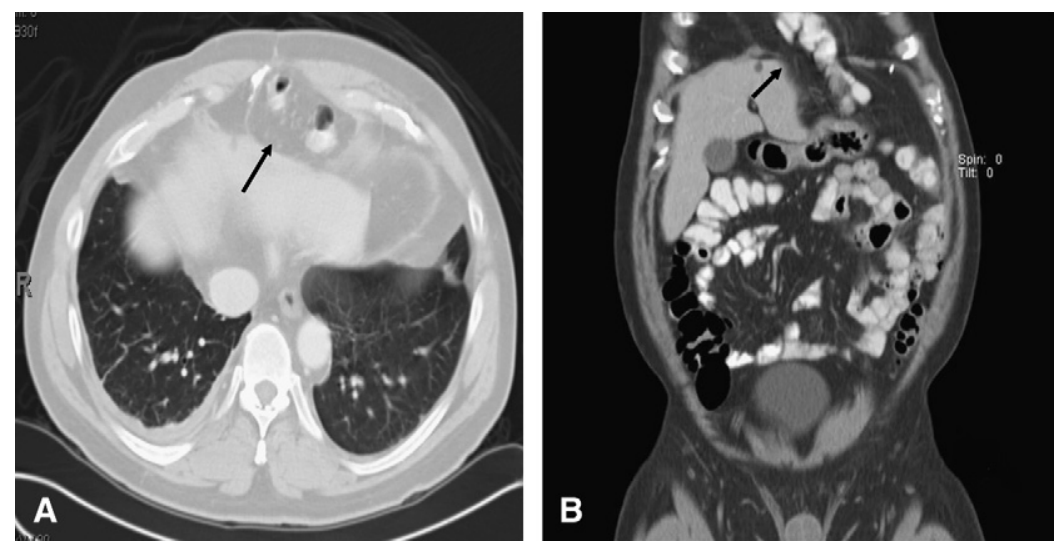

Figure 3. Axial (A) and coronal (B) views of a preoperative computed tomographic scan in a patient with a diaphragmatic hernia after LVAD explantation (arrows point to hernia).

transplant and thoracic surgery clinics. At a median followup time of 18.7 months (range, 1.2-37.2 months), all 5 patients were symptom-free.

\section{Discussion}

At our institution, the incidence of diaphragmatic hernias after patients underwent both LVAD explantation and closure of their cannula defects $(5.2 \%)$ is consistent with the incidence reported in the only other series in the literature $(4.3 \%) .{ }^{4}$ Even though all 5 such patients in our series underwent closure of their cannula defects at the time of their LVAD explantation and were not receiving long-term steroids, all 5 patients nonetheless developed a diaphragmatic hernia. We know that even steroid-free maintenance immunosuppression can contribute to poor healing of the diaphragm after closure of cannula defects. ${ }^{8}$
Note that all of the patients in the aforementioned only other series in the literature ${ }^{4}$ underwent intraperitoneal LVAD placement. In our study, we hypothesized that the risk of diaphragmatic hernias would be much higher after explantation of an intraperitoneal (vs extraperitoneal) LVAD. Therefore, to minimize bias when comparing our results with the other series (in which patients underwent open repair), ${ }^{4}$ we excluded from our analysis patients who underwent explantation of an extraperitoneal LVAD. We found that the proportion of patients who developed a diaphragmatic hernia after explantation of an extraperitoneal LVAD (0 of 28 patients) was lower than after explantation of an intraperitoneal LVAD (5 of 97 patients). However, this difference was not statistically significant (Fisher exact test, $P=.59$ ). Our inability to detect a significant difference may be due to a type II error. Because a relatively small number of

TABLE 1. Characteristics of patients who underwent laparoscopic repair of diaphragmatic hernia after left ventricular assist device explanation

\begin{tabular}{|c|c|c|c|c|c|c|c|c|c|c|c|}
\hline Patient & $\begin{array}{c}\text { Age } \\
\text { (y) }\end{array}$ & Sex & Diagnosis & $\begin{array}{l}\text { Duration of } \\
\text { LVAD use before } \\
\text { OHT (mo) }\end{array}$ & $\begin{array}{c}\text { Repair of cannula } \\
\text { defects at } \\
\text { OHT }\end{array}$ & $\begin{array}{c}\text { Time to } \\
\text { presentation } \\
\text { after } \mathrm{OHT}(\mathrm{mo})\end{array}$ & $\begin{array}{c}\text { Size of } \\
\text { defect }(\mathrm{cm})\end{array}$ & $\begin{array}{c}\text { Location of } \\
\text { hernia }\end{array}$ & Contents & $\begin{array}{l}\text { LOS } \\
\text { (d) }\end{array}$ & $\begin{array}{l}\text { Follow-up } \\
\text { (mo) }\end{array}$ \\
\hline 1 & 57 & M & $\begin{array}{c}\text { Ischemic } \\
\text { cardiomyopathy }\end{array}$ & 3.1 & Primary & 62.3 & 6.0 & $\begin{array}{l}\text { Outflow cannula } \\
\text { defect }\end{array}$ & $\begin{array}{l}\text { Omentum, } \\
\text { stomach }\end{array}$ & 1 & 30.8 \\
\hline 2 & 45 & M & $\begin{array}{c}\text { Idiopathic } \\
\text { cardiomyopathy }\end{array}$ & 3.8 & Primary & 26.3 & 6.0 & $\begin{array}{l}\text { Outflow cannula } \\
\text { defect }\end{array}$ & $\begin{array}{l}\text { Omentum, } \\
\text { colon }\end{array}$ & 4 & 12.5 \\
\hline 3 & 65 & M & $\begin{array}{c}\text { Ischemic } \\
\text { cardiomyopathy }\end{array}$ & 14.7 & Primary & 25.4 & 15.0 & $\begin{array}{l}\text { Outflow cannula } \\
\text { defect }\end{array}$ & $\begin{array}{l}\text { Omentum, } \\
\text { colon }\end{array}$ & 2 & 11.9 \\
\hline 4 & 18 & M & $\begin{array}{c}\text { Familial } \\
\text { cardiomyopathy }\end{array}$ & 1.8 & Primary & 9.0 & 8.0 & $\begin{array}{l}\text { Inflow cannula } \\
\text { defect }\end{array}$ & $\begin{array}{l}\text { Omentum, } \\
\text { stomach }\end{array}$ & 2 & 6.5 \\
\hline 5 & 56 & M & $\begin{array}{c}\text { Idiopathic } \\
\text { cardiomyopathy }\end{array}$ & 13.0 & Mesh & 23.7 & 13.0 & $\begin{array}{l}\text { Inflow cannula } \\
\text { defect }\end{array}$ & $\begin{array}{l}\text { Omentum, } \\
\text { colon, } \\
\text { small } \\
\text { intestine }\end{array}$ & 4 & 1.1 \\
\hline Median & 56 & & & 6.8 & & 25.4 & 8.0 & & & 2 & 12.2 \\
\hline
\end{tabular}

$\angle V A D$, Left ventricular assist device; $O H T$, orthotopic heart transplant; $L O S$, length of stay. 

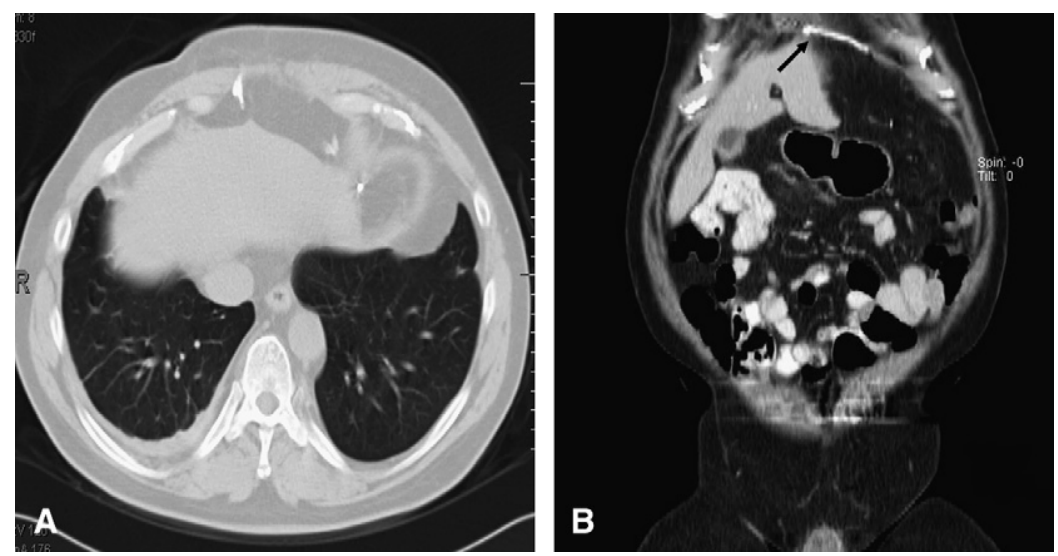

Figure 4. Axial (A) and coronal (B) views of a postoperative computed tomographic scan in the same patient, demonstrating a durable hernia repair (arrow points to polytetrafluoroethylene patch).

extraperitoneal LVADs have been explanted at our institution, our study may lack sufficient statistical power to detect a significant difference.

Clearly, if the peritoneum is violated, diaphragmatic hernias can and do occur after explantation of an intracorporeal extraperitoneal LVAD. Of the 14 patients reported in the literature who developed a diaphragmatic hernia after LVAD explantation $^{4-7}$ (as well in as our series), only 1 developed a diaphragmatic hernia after explantation of an extraperitoneal LVAD. ${ }^{7}$ In the future, as more patients with extraperitoneal LVADs undergo explantation, a more accurate assessment of the risk of diaphragmatic hernias may be possible. Regardless of whether an LVAD is placed intraperitoneally or extraperitoneally, the diaphragmatic defects should be repaired at the time of explantation, given the significant risk $(15.9 \%)^{4}$ and the associated morbidity of a diaphragmatic hernia if such defects are not immediately repaired. Unless the risk of infection is prohibitively high, mesh should be used to repair large cannula defects.

The time to diagnosis of diaphragmatic hernias after LVAD explantation varies widely: from 6 months to more than 60 months after OHT. ${ }^{4,5,7}$ Consequently, all patients who undergo OHT and intraperitoneal LVAD explantation, and who develop upper abdominal pain or anterior chest discomfort should undergo imaging (ie, chest x-ray or computed tomography) to evaluate for the presence of a diaphragmatic hernia, regardless of whether or not their diaphragmatic cannula defects were closed at the time of their OHT.

Diaphragmatic hernias after LVAD explantation were first described in $1992 .{ }^{5}$ Since then, only 4 other reports have discussed the presenting symptoms and the outcomes after repair of these hernias, despite the burgeoning use of LVADs and presumably a growing prevalence of these hernias. ${ }^{4-7}$ Moreover, little attention has been devoted to the technical aspects of repairing these hernias. Because of the large size of the hernias in our study (median, $8 \mathrm{~cm}$ ), a polytetrafluoroethylene patch was required to perform a tension-free repair.
To secure the patch over the defect, we used pledget-reinforced, 0 silk, handsewn mattress sutures on an $\mathrm{SH}$ needle and then reinforced the repair with laparoscopic tacking screws to close any potential small gaps between the sutures. We prefer these handsewn stitches to automatic laparoscopic stitching devices because the $\mathrm{SH}$ needle allows deeper and wider tissue bites under direct visualization. Theoretically, the pledgets could erode through the diaphragm or into other viscera, but we have not encountered this complication in this series or in our previous series of laparoscopic repair of giant hiatal hernias (in which a crural repair was performed with a similar stitch). ${ }^{9}$

The few reports in the literature of diaphragmatic hernias after LVAD explantation did not describe the OR time. Compared with the OR time of reports in the literature of laparoscopic repair of traumatic diaphragmatic hernias (range, 55-200 minutes), our OR time (range, 182-345 minutes) was longer. ${ }^{10,11}$ However, repair of diaphragmatic hernias after LVAD explantation can be technically challenging. For instance, several of our 5 patients required meticulous adhesiolysis to separate herniated viscera from their cardiac allografts. Despite the technical challenges, we believe that laparoscopic repair has several distinct advantages: (1) reduced immunologic stress, compared with laparotomy; ${ }^{12-14}$ (2) better visualization and mobilization of the hernia sac in the mediastinum, thereby sparing the patient a thoracoscopy or thoracotomy; (3) earlier resumption of oral intake, allowing patients to continue their immunosuppression without interruption; (4) shorter length of stay, compared with open repair; and (5) better cosmesis, compared with laparotomy.

\section{Conclusions}

Laparoscopic repair of diaphragmatic hernias resulting from vulnerable locations in the diaphragm created by LVAD explantation can be performed with minimal morbidity, a brief length of stay, and excellent short-term results. 
We thank Mary Knatterud, $\mathrm{PhD}$, for invaluable editorial assistance and Shawn Roerick, RN, BSN, for assistance, in compiling information on our patients with LVADs.

\section{References}

1. Rosamond W, Flegal K, Friday G, Furie K, Go A, Greenlund K, et al. Heart disease and stroke statistics-2007 update: a report from the American Heart Association Statistics Committee and Stroke Statistics Subcommittee. Circulation. 2007;115:e69-171.

2. The Organ Procurement and Transplant Network, Transplants by Donor Type, U.S. Transplants Performed: January 1, 1988-April 30, 2007. United Network for Organ Sharing website. Available at: http:// www.optn.org/latestData/rptData.asp. Accessed April 30, 2007.

3. Mancini D, Burkhoff D. Mechanical device-based methods of managing and treating heart failure. Circulation. 2005;112:438-48.

4. Chatterjee S, Williams NN, Ohara ML, Twomey C, Morris JB, Acker MA. Diaphragmatic hernias associated with ventricular assist devices and heart transplantation. Ann Thorac Surg. 2004;77:2111-4.

5. Phillips WS, Burton NA, Macmanus Q, Lefrak EA. Surgical complications in bridging to transplantation: the Thermo Cardiosystems LVAD. Ann Thorac Surg. 1992;53:482-6.

6. Mouly-Bandini A, Chalvignac V, Collart F, Caus T, Guidon C, Giudicelli R, et al. Transdiaphragmatic hernia 1 year after heart transplantation following implantable LVAD. $J$ Heart Lung Transplant. 2002;21:1144-6.
7. Farma J, Leeser D, Furukawa S, Dempsey DT. Laparoscopic repair of diaphragmatic hernia after left ventricular assist device. J Laparoendosc Adv Surg Tech A. 2003;13:185-7.

8. Kobashigawa JA, Miller LW, Russell SD, Ewald GA, Zucker MJ, Goldberg LR, et al. Tacrolimus with mycophenolate mofetil (MMF) or sirolimus vs. cyclosporine with MMF in cardiac transplant patients: 1-year report. Am J Transplant. 2006;6:1377-86.

9. Whitson BA, Hoang CD, Boettcher AK, Dahlberg PS, Andrade RS, Maddaus MA. Wedge gastroplasty and reinforced crural repair: important components of laparoscopic giant or recurrent hiatal hernia repair. J Thorac Cardiovasc Surg. 2006;132:1196202.e3.

10. Matthews BD, Bui H, Harold KL, Kercher KW, Adrales G, Park A, et al. Laparoscopic repair of traumatic diaphragmatic injuries. Surg Endosc. 2003;17:254-8

11. Huttl TP, Lang R, Meyer G. Long-term results after laparoscopic repair of traumatic diaphragmatic hernias. J Trauma. 2002;52:562-6.

12. Nguyen NT, Goldman CD, Ho HS, Gosselin RC, Singh A, Wolfe BM. Systemic stress response after laparoscopic and open gastric bypass. J Am Coll Surg. 2002;194:557-67.

13. Ordemann J, Jacobi CA, Schwenk W, Stosslein R, Muller JM. Cellular and humoral inflammatory response after laparoscopic and conventional colorectal resections. Surg Endosc. 2001;15:600-8.

14. Wichmann MW, Huttl TP, Winter H, Spelsberg F, Angele MK, Heiss MM, et al. Immunological effects of laparoscopic vs open colorectal surgery: a prospective clinical study. Arch Surg. 2005;140:692-7. 